\title{
CARACTERIZAÇÃO FITOSSOCIOLÓGICA DE UM REMANESCENTE DE FLORESTA OMBRÓFILA MISTA EM GUARAPUAVA, PR ${ }^{1}$
}

\author{
Juliano Cordeiro² e William Antônio Rodrigues ${ }^{3}$
}

\begin{abstract}
RESUMO - A Floresta Ombrófila Mista constituiu padrão referencial da flora do Paraná. O Parque Municipal das Araucárias localiza-se no Município de Guarapuava, PR, e abriga uma área de 41 ha de floresta em estado natural. Foram instaladas 32 parcelas de 10 x 10 m e mensurados 447 indivíduos com diâmetro à altura do peito (DAP) igual ou superior a 4,8 cm, ou numa média de 1.397 indivíduos/ha. A estrutura horizontal da floresta é caracterizada por cinco espécies: Araucaria angustifolia (Bertol.) Kuntze, Campomanesia xanthocarpa (Mart.) O. Berg, Casearia decandra Jac, Capsicodendron dinisii (Schwacke) Occhioni e Allophylus edulis (A. St.-Hil.) Radlk. ex Warm., que juntas somaram 64,85\% do total de VI, 74,36\% do valor de cobertura, $87,63 \%$ da dominância e $61,07 \%$ do número de indivíduos amostrados. Foi possível definir três estratos de altura: estrato inferior - até $5,99 \mathrm{~m}$, estrato médio - entre 6,0 e 10,99 m e estrato superior - maior que $11 \mathrm{~m}$. Os diâmetros dos indivíduos amostrados, distribuídos em 22 classes diamétricas, variaram de 4,8 a 114,7 $\mathrm{cm}$. O índice de diversidade de Shannon-Weaver calculado foi de 2,79 nats/indivíduo e o índice de uniformidade de Pielou, igual a 0,9 .
\end{abstract}

Palavras-chave: Fitossociologia, floresta ombrófila mista e araucária.

\section{PHYTOSOCIOLOGICAL CHARACTERIZATION OF A MIXED OMBROPHYLOUS FOREST REMNANT IN GUARAPUAVA, PR}

\begin{abstract}
The Mixed Ombrophylous Forest (MOF) or Araucaria Forest was used as reference pattern for the flora of Paraná. The Araucaria Municipal Park is located in Guarapuava-PR and comprises an area of 41 ha of Mixed Ombrophylous Forest. In this area, $3210 \times 10 \mathrm{~m}$ plots were installed and 447 individuals with diameter of breast height (DBH) equal or above to $4.8 \mathrm{~cm}$ were measured, or an average of 1397 individuals per hectare. Forest horizontal structure is characterized by five species-Araucaria angustifolia (Bertol.) Kuntze, Campomanesia xanthocarpa (Mart.) O. Berg, Casearia decandra Jac, Capsicodendron dinisii (Schwacke) Occhioni and Allophylus edulis (A. St. - Hil.) Radlk. ex Warm., which added together $64.85 \%$ of the VI total, $74.36 \%$ of the cover value, $87.63 \%$ of dominance and $61.07 \%$ of sampled individuals. Three height strata were defined - inferior stratum - up to $5.99 \mathrm{~m}$, medium stratum - between 6 and $10.99 \mathrm{~m}$ and superior stratum - higher than $11 \mathrm{~m}$. The diameters of the sampled individuals ranged from 4.8 to $114.7 \mathrm{~cm}$ distributed in 22 diameter classes. The calculated Shannon-Weaver diversity index was 2.79 nats/individual and the Pielou index of uniformity was 0.9 .
\end{abstract}

Keywords: Floristic, phytosociology and Mixed Ombrophylous Forest.

\footnotetext{
${ }^{1}$ Recebido em 09.08.2006 e aceito para publicação em 13.04.2007

${ }^{2}$ Programa de Pós-Graduação em Engenharia Florestal da Universidade Federal do Paraná, Rua Lothário Meissner, 632, Jardim Botânico, CAMPUS III, 80210-170 Curitiba-PR. E-mail: <cordeirojuliano@yahoo.com.br>.

${ }^{3}$ Programa de Pós-Graduação em Botânica da Universidade Federal do Paraná, Centro Politécnico - Jardim das Américas Caixa Postal 19031, 81531-970 Curitiba-PR. E-mail: <william@ufpr.br>.
} 


\section{INTRODUÇÃO}

O Brasil possui dimensões continentais e abriga grande diversidade florística, sendo a Floresta Ombrófila Mista (FOM) definida como uma das suas regiões fitoecológicas, de acordo com a classificação da vegetação brasileira (IBGE, 1992). Segundo Klein (1960), a FOM apresenta ocorrência preferencial nos estados do Sul do Brasil, sendo inconfundível fisionomicamente devido à presença da Araucaria angustifolia como espécie típica e caracterizadora desse bioma.

No Paraná, o tipo de vegetação mais representativa era a FOM, que ocupava uma área de 7.378.000 há, ou $37 \%$ da superfície original do território paranaense (MAACK, 1981). Entretanto, a FOM iniciou o novo milênio com apenas $0,8 \%$ de seus remanescentes naturais em estágio avançado de sucessão, fragmentados ao longo dos três planaltos do Estado (FUPEF, 2001). O Município de Guarapuava, juntamente com outros 17 municípios, forma a microrregião Campos de Guarapuava, que ocupa o $1^{\circ}$ lugar no ranking de florestas naturais do Paraná, com $15,22 \%$ de áreas cobertas por florestas, sendo a FOM a principal formação vegetacional (SPVS, 1996).

Pela sua localização no terceiro planalto paranaense e região Centro-Oeste do Estado, o rol de fatores abióticos, como altitude, solos, clima (temperatura, precipitação e geadas, entre outros) que ocorrem no Município de Guarapuava, podem, conforme Klein (1984) e Matteucci e Colma (1982), influenciar as diferenciações da vegetação de uma região. Para Romariz (1972), as florestas poderão apresentar diferentes características, segundo a sua disposição quanto ao relevo, à latitude, à altitude, e à maior ou menor proximidade com o oceano, entre outros.

Os remanescentes de FOM do terceiro planalto paranaense são pouco estudados, fato comprovado por Isernhagen (2001), que das 162 referências sobre trabalhos florísticos e fitossociológicos das formações vegetacionais realizados no Estado do Paraná, nas últimas duas décadas, apenas 40 eram em FOM e, desses, somente um foi realizado na região Centro-Oeste. $\mathrm{O}$ objetivo deste trabalho foi quantificar os parâmetros fitossociológicos das estruturas horizontal e vertical de um remanescente de FOM na região Centro-Oeste do Estado do Paraná.

\section{MATERIAL E MÉTODOS}

O Parque Municipal das Araucárias (PMA) localizase no Município de Guarapuava, PR (Figura 1), com as coordenadas geográficas $25^{\circ} 21^{\prime} 06^{\prime \prime} \mathrm{S}$ e $51^{\circ} 28^{\prime} 08^{\prime}$ "
W. O histórico do PMA revela que, no passado, houve corte seletivo de algumas espécies do subosque para facilitar o manejo de eqüinos reprodutores que eram criados na área. Também foram abertas trilhas ecológicas no interior da floresta para permitir a visitação e realização de práticas de educação ambiental. Contudo, não se verificaram sinais de perturbações mais agressivas como desmatamento, com a retirada de essências florestais. A área do PMA é de aproximadamente 104 ha, com 41 ha ocupados pela FOM (GUARAPUAVA, 2006).

O clima da região, segundo a classificação de Köppen, é do tipo Cfb, sem estação seca (MAACK, 1981). A temperatura média do ar do mês mais quente é em torno de $20,9^{\circ} \mathrm{C}$ e a média do mês mais frio, 8,4 ${ }^{\circ} \mathrm{C}$. Quanto à umidade relativa do ar, as médias mínimas e máximas registradas atingiram 74 e $81 \%$, respectivamente. Sobre a velocidade e direção dos ventos, a maior média registrada foi de $3,4 \mathrm{~m} / \mathrm{s}$ e a menor, $2,5 \mathrm{~m} / \mathrm{s} \mathrm{NE}$. Os índices de precipitação médios apontaram 93,9 $\mathrm{mm}$ mo mês mais seco e 202,6 mm no mais chuvoso, com um mínimo de 8 e máximo de 16 dias por mês de chuva. Em relação à evaporação, o menor registro foi de 52,4 mm e o maior, $81,7 \mathrm{~mm}$ mensais. Todos os dados climáticos médios referentes aos últimos 28 anos foram obtidos da Estação Meteorológica de Guarapuava pertencente ao Instituto Agromônico do Paraná, que dista 4 km, em linha reta, da área estudada (IAPAR, 2006).

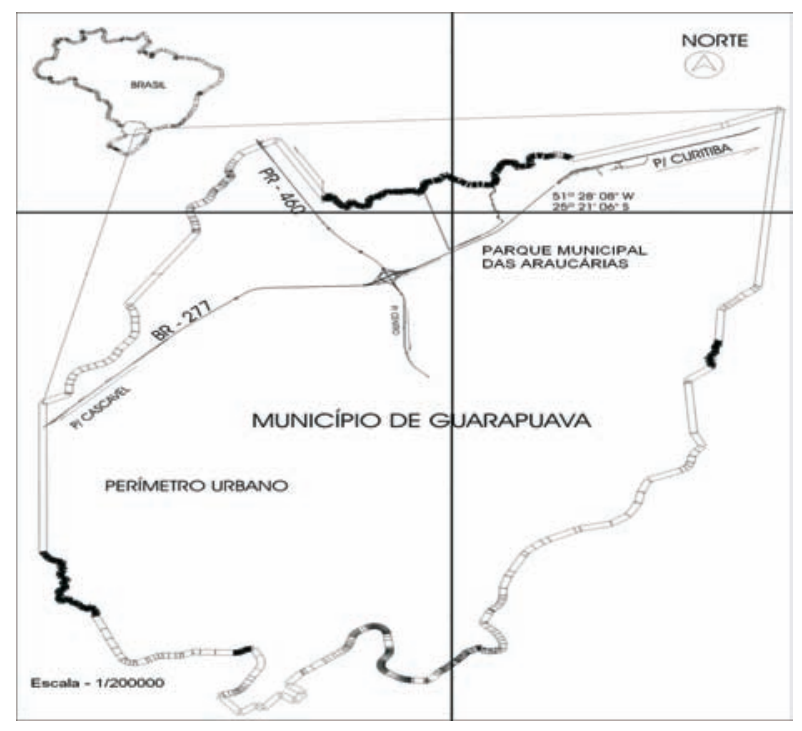

Fonte: SEMAFLOR (2005).

Figura 1 - Localização do Parque Municipal das Araucárias, em Guarapuava, PR.

Figure 1 -Location of Araucarias Municipal Park, Guarapuava, $P R$. 
A unidade pedológica predominante é o Latossolo Bruno Álico A proeminente textura argilosa (IAPAR, 1986), ocorrendo também associações de Latossolo Bruno Álico mais Cambissolo Álico (SILVA, 2003), solos litólicos nas vertentes mais íngremes e na posição de plano aluvial Glei Húmico e Orgassolos (RODERJAN et al., 1991). O relevo da área da floresta apresenta três variações bem distintas, suave-ondulado a ondulado na porção superior, médio-ondulado na porção mediana e plano na porção inferior que margeia o rio Xarquinho. A altitude do Parque fica em torno dos 1.070 m.s.n.m. (GUARAPUAVA, 2006).

Para o levantamento fitossociológico, foram instaladas 32 parcelas de $10 \times 10 \mathrm{~m}$., sendo mensurados todos os indivíduos com diâmetro à altura do peito (DAP) igual ou superior a $4,8 \mathrm{~cm}$. Cada indivíduo foi localizado no croqui da respectiva parcela, sendo anotados os valores de perímetro e altura total e coleta de material vegetativo ou fértil para determinação da espécie, sendo as parcelas de forma contígua e em linhas com espaçamento mímino de $2 \mathrm{~m}$ cada parcela. Procurou-se manter a homogeneidade da unidade pedológica e fisionomia vegetacional, evitando as margens da floresta e das trilhas e as clareiras naturais surgidas pela queda das árvores maiores, principlamente dos pinheiros. A ordenação das famílias e gêneros foi baseado no APG II, e a nomenclatura das espécies foi verificada nos arquivos on-line do Missouri Botanical Garden disponível na página < http://mobot.mobot.org/ W3T/Search/vast.html>.

Os dados coletados foram ordenados e processados com o uso do software "Mata Nativa" (CIATEC, 2001). As variáveis fitossociológicas calculadas foram: densidade, freqüência, dominância, valor de importância e valor de cobertura (MUELLER-DUMBOIS e ELLENBERG, 1974). Para o estudo da diversidade foram calculados o índice de diversidade de Shannon-Weaver (H') e o índice de uniformidade de Pielou (J) (MAGURRAN, 1988). Com o emprego do software Biodiversity version 2, foram processadas análises pelo método de ligação completa baseada na distância euclidiana para agrupamentos das espécies pelo valor de importância (VI\%). A suficiência amostral (Figura 2) foi determinada pela curva espéciesárea(BRAUN-BLANQUET, 1950; RICEe KELTING 1955). A definição dos estratos do remanescente florestal foi baseada na metodologia empregada por Longhi e Faehser (1980), em que cada estrato deveria conter aproximadamente $33,33 \%$ das frequiências acumuladas das alturas dos indivíduos amostrados, ficando os limites entre os estratos da seguinte forma: Inferior - alturas menores que 5,99 m; Médio-alturas entre 6,0 e 10,99 m; e Superior-alturas maiores que $11 \mathrm{~m}$. Para o diâmetro, foram encontradas 22 classes diamétricas, com intervalos de $5 \mathrm{~cm}$ entre elas.

\section{RESULTADOS E DISCUSSÃO}

As 32 parcelas instaladas perfizeram uma área de 0,32 ha, onde foram mensurados 447 indivíduos que proporcionalmente representam uma média de 1.397 indivíduos/ha. As árvores mortas em pé foram reunidas na categoria Mortas, uma vez que não foi possível a identificação no campo, apenas calculados seus valores fitossociológicos. O Quadro 1 relaciona os valores dos parâmetros calculados para as espécies encontradas no remanescente florestal estudado.

Com base na variável valor de importância porcentual (VI\%), as espécies ficaram agrupadas da seguinte forma: Grupo 1 - formado por cinco espécies, que juntas somaram $64,85 \%$ do total de VI, 74,36\% do valor de cobertura (VC), $87,63 \%$ da dominância relativa (DoR), 61,07\% do número de indivíduos amostrados e $11,01 \%$ da diversidade quanto ao número de espécies. Grupo 2 -formado por 13 espécies classificadas da $6^{\mathrm{a}}$ à $18^{\mathrm{a}}$ posição pelo VI. Essas espécies juntas somaram 20,86\% do total de VI, $15,68 \%$ do VC, $8,52 \%$ da DoR, $22,81 \%$ do número de indivíduos amostrados e 28,88\% do número de espécies. Grupo 3 -com 27 espécies, que ocuparam da $18^{\mathrm{a}}$ à $45^{\mathrm{a}}$ posição, respondem por $8,44 \%$ do VI, $5,17 \%$ do VC, $1,82 \%$ da DoR, $8,5 \%$ do número de indivíduos e $60 \%$ das espécies amostradas. Grupo $4-$ foi formado pelos indivíduos mortos, que somaram $5,84 \%$ do total de VI, 4,81\% do VC, 2,01\% da DoR e 7,60\% do número de indivíduos amostrados. A ordenação dos grupos encontra-se no Quadro 1 e o dendrograma do agrupamento das espécies pelo VI\%, na Figura 3.

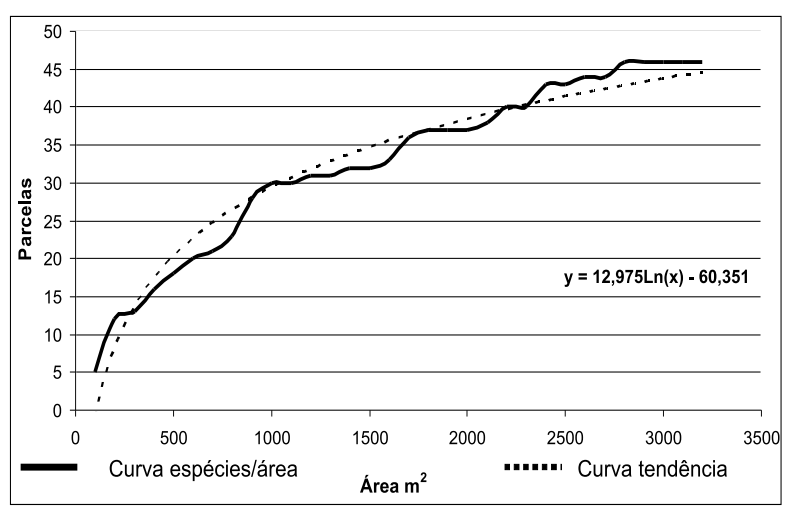

Figura 2 - Curva de espécies/área do remanescente de FOM do Parque Municipal das Araucárias, em Guarapuava, PR.

Figure 2-Curve species/area of a MOF remnant in the Araucaria Municipal Park, Guarapuava, PR.

R. Árvore, Viçosa-MG, v.31, n.3, p.545-554, 2007 
Quadro 1 - Valores dos parâmetros fitossociológicos das espécies encontradas no remanescente Floresta Ombrófila Mista do Parque Municipal das Araucárias em Guarapuava, Paraná

Table 1 - Phytosociological parameters for the species found within the Mixed Ombrophylous Forest remnant in the Araucaria Municipal Park, Guarapuava - Paraná

\begin{tabular}{|c|c|c|c|c|c|c|c|c|c|c|c|c|}
\hline $\begin{array}{l}\text { Grupo/ } \\
\text { Ordem }\end{array}$ & Nome Científico & ni & $\mathrm{DA}$ & $\mathrm{DR}$ & FA & FR & DoA & DoR & $\mathrm{VC}$ & $\begin{array}{l}\mathrm{VC} \\
(\%) \\
\end{array}$ & VI & $\begin{array}{c}\mathrm{VI} \\
(\%) \\
\end{array}$ \\
\hline 1.1 & Araucaria angustifolia (Bertol.) Kuntze & 44 & 137,50 & 9,84 & 75 & 9,49 & 50437 & 68,93 & 78,78 & 39,39 & 88,26 & 29,42 \\
\hline 1.2 & $\begin{array}{l}\text { Campomanesia xanthocarpa (Mart.) } \\
\text { O. Berg }\end{array}$ & 105 & 328,13 & 23,49 & 100 & 12,65 & 7250 & 9,91 & 33,4 & 16,7 & 46,05 & 15,35 \\
\hline 1.3 & Casearia decandra Jac. & 62 & 193,75 & 13,87 & 84,38 & 10,67 & 1756 & 2,40 & 16,27 & 8,14 & 26,94 & 8,98 \\
\hline 1.4 & $\begin{array}{l}\text { Capsicodendron dinisii } \\
\text { (Schwacke) Occhioni }\end{array}$ & 25 & 78,13 & 5,59 & 43,75 & 5,53 & 4048 & 5,53 & 11,13 & 5,56 & 16,66 & 5,55 \\
\hline 1.5 & $\begin{array}{l}\text { Allophylus edulis (A. St.-Hil.) } \\
\text { Radlk. ex Warm. }\end{array}$ & 37 & 115,63 & 8,28 & 59,38 & 7,51 & 0,627 & 0,86 & 9,13 & 4,57 & 16,64 & 5,55 \\
\hline 2.1 & Zanthoxylum rhoifolium Lam. & 15 & 46,88 & 3,36 & 31,25 & 3,95 & 0,593 & 0,81 & 4,17 & 2,08 & 8,12 & 2,71 \\
\hline 2.2 & $\begin{array}{l}\text { Sebastiania commersoniana (Baill.) } \\
\text { J. B. Smith \& R. J. Downs }\end{array}$ & 18 & 56,25 & 4,03 & 21,88 & 2,77 & 0,753 & 1,03 & 5,06 & 2,53 & 7,82 & 2,61 \\
\hline 2.3 & Strychnos brasiliensis (Spreng.) Mart. & 14 & 43,75 & 3,13 & 34,38 & 4,35 & 0,22 & 0,30 & 3,43 & 1,72 & 7,78 & 2,59 \\
\hline 2.4 & Dicksonia sellowiana Hook. & 6 & 18,75 & 1,34 & 18,75 & 2,37 & 1134 & 1,55 & 2,89 & 1,45 & 5,26 & 1,75 \\
\hline 2.5 & Styrax leprosus Hook. et Arn. & 9 & 28,13 & 2,01 & 21,88 & 2,77 & 0,147 & 0,20 & 2,21 & 1,11 & 4,98 & 1,66 \\
\hline 2.6 & Vitex megapotamica (Spreng.) Mold. & 6 & 18,75 & 1,34 & 15,63 & 1,98 & 1155 & 1,58 & 2,92 & 1,46 & 4,9 & 1,63 \\
\hline 2.7 & Alsophila setosa Kaulf. & 6 & 18,75 & 1,34 & 18,75 & 2,37 & 0,71 & 0,97 & 2,31 & 1,16 & 4,68 & 1,56 \\
\hline 2.8 & Ilex brevicuspis Reiss. & 5 & 15,63 & 1,12 & 15,63 & 1,98 & 0,544 & 0,74 & 1,86 & 0,93 & 3,84 & 1,28 \\
\hline 2.9 & Ilex theezans Mart. & 5 & 15,63 & 1,12 & 15,63 & 1,98 & 0,129 & 0,18 & 1,29 & 0,65 & 3,27 & 1,09 \\
\hline 2.10 & $\begin{array}{l}\text { Drymis brasiliensis Miers subsp. sylvatica } \\
\text { (A. St.-Hil.) Ehrend. \& Gottsb. }\end{array}$ & 5 & 15,63 & 1,12 & 15,63 & 1,98 & 0,105 & 0,14 & 1,26 & 0,63 & 3,24 & 1,08 \\
\hline 2.11 & Ilex paraguariensis A. St.-Hil. & 4 & 12,50 & 0,89 & 12,5 & 1,58 & 0,448 & 0,61 & 1,51 & 0,75 & 3,09 & 1,03 \\
\hline 2.12 & Sapium glandulatum (Vell.) Pax & 5 & 15,63 & 1,12 & 12,5 & 1,58 & 0,121 & 0,17 & 1,28 & 0,64 & 2,87 & 0,96 \\
\hline 2.13 & Jacaranda puberula Cham. & 4 & 12,50 & 0,89 & 12,5 & 1,58 & 0,177 & 0,24 & 1,14 & 0,57 & 2,72 & 0,91 \\
\hline 3.1 & Cinnamomum amoenum (Ness) Kostermans & 3 & 9,38 & 0,67 & 9,38 & 1,19 & 0,17 & 0,23 & 0,9 & 0,45 & 2,09 & 0,70 \\
\hline 3.2 & Casearia obliqua Sprengel & 2 & 6,25 & 0,45 & 6,25 & 0,79 & 0,316 & 0,43 & 0,88 & 0,44 & 1,67 & 0,56 \\
\hline 3.3 & Ocotea pulchella Mart. & 2 & 6,25 & 0,45 & 6,25 & 0,79 & 0,11 & 0,15 & 0,6 & 0,3 & 1,39 & 0,46 \\
\hline 3.4 & Solanum sanctaecatharinae Dun. & 2 & 6,25 & 0,45 & 6,25 & 0,79 & 0,101 & 0,14 & 0,59 & 0,29 & 1,38 & 0,46 \\
\hline 3.5 & Dalbergia frutescens (Vell.) Britton & 2 & 6,25 & 0,45 & 6,25 & 0,79 & 0,036 & 0,05 & 0,50 & 0,25 & 1,29 & 0,43 \\
\hline 3.6 & Eugenia pyriformis Camp. & 2 & 6,25 & 0,45 & 6,25 & 0,79 & 0,033 & 0,04 & 0,49 & 0,25 & 1,28 & 0,43 \\
\hline 3.7 & Ocotea porosa (Ness \& Mart.) Barroso & 2 & 6,25 & 0,45 & 6,25 & 0,79 & 0,027 & 0,04 & 0,48 & 0,24 & 1,28 & 0,43 \\
\hline 3.8 & Lithraea aroeirinha March. ex Waib & 2 & 6,25 & 0,45 & 6,25 & 0,79 & 0,023 & 0,03 & 0,48 & 0,24 & 1,27 & 0,42 \\
\hline 3.9 & Matayba elaeagnoides Radlk. & 2 & 6,25 & 0,45 & 6,25 & 0,79 & 0,021 & 0,03 & 0,48 & 0,24 & 1,27 & 0,42 \\
\hline 3.10 & Ligustrum lucidum W. T. Aiton & 2 & 6,25 & 0,45 & 6,25 & 0,79 & 0,016 & 0,02 & 0,47 & 0,23 & 1,26 & 0,42 \\
\hline 3.11 & Ocotea puberula (Rich.) Ness. & 1 & 3,13 & 0,22 & 3,13 & 0,40 & 0,146 & 0,20 & 0,42 & 0,21 & 0,82 & 0,27 \\
\hline 3.12 & $\begin{array}{l}\text { Myrsine coriaecea }(\text { Sw. }) \\
\text { R. Br. ex Roem. \& Schult. }\end{array}$ & 1 & 3,13 & 0,22 & 3,13 & 0,40 & 0,072 & 0,10 & 0,32 & 0,16 & 0,72 & 0,24 \\
\hline 3.13 & Prunus sellowii Koehne & 1 & 3,13 & 0,22 & 3,13 & 0,40 & 0,062 & 0,08 & 0,31 & 0,15 & 0,7 & 0,23 \\
\hline 3.14 & Symplocus uniflora (Pohl) Benth. & 1 & 3,13 & 0,22 & 3,13 & 0,40 & 0,039 & 0,05 & 0,28 & 0,14 & 0,67 & 0,22 \\
\hline 3.15 & Myrcia guianensis (Aubl.) DC. & 1 & 3,13 & 0,22 & 3,13 & 0,40 & 0,032 & 0,04 & 0,27 & 0,13 & 0,66 & 0,22 \\
\hline 3.16 & Solanum caeruleum Vell. & 1 & 3,13 & 0,22 & 3,13 & 0,40 & 0,023 & 0,03 & 0,26 & 0,13 & 0,65 & 0,22 \\
\hline 3.17 & Solanum granulosoleprosum Dun. & 1 & 3,13 & 0,22 & 3,13 & 0,40 & 0,017 & 0,02 & 0,25 & 0,12 & 0,64 & 0,21 \\
\hline 3.18 & Schinus terebinthifolius Raddi & 1 & 3,13 & 0,22 & 3,13 & 0,40 & 0,017 & 0,02 & 0,25 & 0,12 & 0,64 & 0,21 \\
\hline 3.19 & Erythroxylum deciduum A. St.-Hil. & 1 & 3,13 & 0,22 & 3,13 & 0,40 & 0,015 & 0,02 & 0,24 & 0,12 & 0,64 & 0,21 \\
\hline 3.20 & Citrus reticulata Blanco & 1 & 3,13 & 0,22 & 3,13 & 0,40 & 0,012 & 0,02 & 0,24 & 0,12 & 0,64 & 0,21 \\
\hline
\end{tabular}

R. Árvore, Viçosa-MG, v.31, n.3, p.545-554, 2007 
Quadro 1 - Cont.

Table 1 - Cont

\begin{tabular}{llccccccccccc}
\hline $\begin{array}{l}\text { Grupo/ } \\
\text { Ordem }\end{array}$ & Nome Científico & ni & DA & DR & FA & FR & DoA & DoR & $\begin{array}{c}\text { VC } \\
\text { VC } \\
(\%)\end{array}$ & $\begin{array}{c}\text { V } \\
\text { V } \\
(\%)\end{array}$ \\
\hline 3.21 & Eugenia uniflora L. & 1 & 3,13 & 0,22 & 3,13 & 0,40 & 0,011 & 0,02 & 0,24 & 0,12 & 0,63 & 0,21 \\
3.22 & Cestrum amictum Schltcht. & 1 & 3,13 & 0,22 & 3,13 & 0,40 & 0,01 & 0,01 & 0,24 & 0,12 & 0,63 & 0,21 \\
3.23 & Schinus johnstonii Barkl. & 1 & 3,13 & 0,22 & 3,13 & 0,40 & 0,008 & 0,01 & 0,23 & 0,12 & 0,63 & 0,21 \\
3.25 & Banara tomentosa Clos. & 1 & 3,13 & 0,22 & 3,13 & 0,40 & 0,007 & 0,01 & 0,23 & 0,12 & 0,63 & 0,21 \\
3.26 & Vassobia breviflora (Sendtn.) Hunz. & 1 & 3,13 & 0,22 & 3,13 & 0,40 & 0,006 & 0,01 & 0,23 & 0,12 & 0,63 & 0,21 \\
3.24 & Eugenia uruguayensis Cambess. & 1 & 3,13 & 0,22 & 3,13 & 0,40 & 0,008 & 0,01 & 0,23 & 0,12 & 0,63 & 0,21 \\
3.27 & Myrcia venulosa DC. & 1 & 3,13 & 0,22 & 3,13 & 0,40 & 0,006 & 0,01 & 0,23 & 0,12 & 0,63 & 0,21 \\
4 & Mortas & 34 & 106,25 & 7,61 & 62,5 & 7,91 & 1.469 & 2,01 & 9,61 & 4,81 & 17,52 & 5,84 \\
\hline & Total & 447 & 1397 & 100 & 790 & 100 & 67254 & 100 & 200 & 100 & 300 & 100 \\
\hline
\end{tabular}

$\mathrm{ni}=\mathrm{n}^{\circ}$ de indivíduos coletados; $\mathrm{DA}=$ densidade absoluta em $\mathrm{n}^{\circ}$ de indivíduos, $\mathrm{DR}=$ densidade relativa em $\%, \mathrm{FA}=$ frequiência absoluta $\mathrm{em} \%, \mathrm{FR}=$ frequiência relativa $\mathrm{em} \%, \mathrm{DoA}=$ dominância absoluta $\mathrm{em} \mathrm{m}^{2} / \mathrm{ha}, \mathrm{DoR}=$ dominância relativa em $\%, \mathrm{VC}=\mathrm{valor}$ de cobertura em $\%$, VC $\%=$ valor de cobertura relativo em $\%$, VI = valor de importância em $\%$, e VI \% = valor de importância relativo em $\%$.

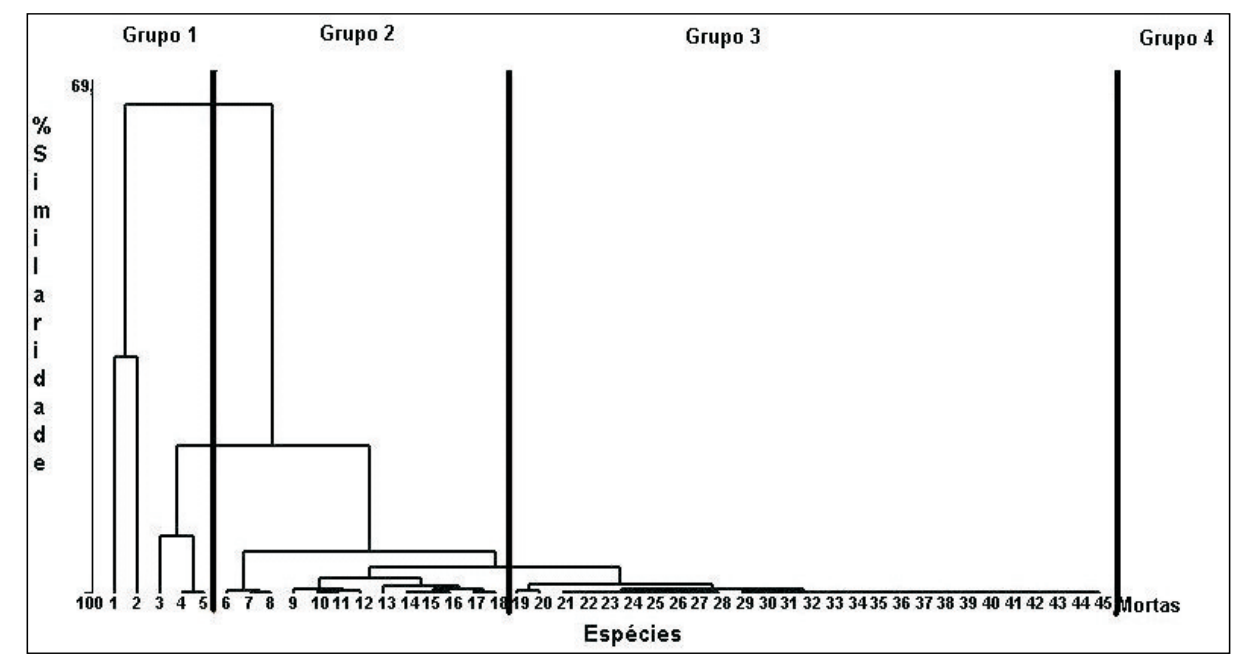

Figura 3 - Agrupamento das espécies baseado no valor de importância (VI\%) em razão da distância euclidiana (Ligação completa).

Figure 3 - Species grouping based on the importance value (VI\%) using Euclidian distance (Complete Connection).

A análise dos dados mostrou que as cinco espécies do Grupo 1 - Araucaria angustifolia, Campomanesia xanthocarpa, Casearia decandra, Capsicodendron dinisii e Allophylus edulis eram as mais importantes na estrutura do remanescente estudado. De maneira geral, os dados encontrados nessas cinco espécies foram registrados em menor ou maior grau de importância na estrutura dos remanescentes de FOM por Silva et al. (1998), Nascimento et al. (2001), Negrelle e Leuchtenberger (2001), Rondon Neto et al. (2002a), Roderjan (2003) e Silva (2003), entre outros. A Araucaria angustifólia, com $88,26 \%$ de VI $(29,42 \%$ do total) e $39,39 \%$ do VC, foi a terceira espécie mais freqüente
(75\% de FA), com destaque para a dominância absoluta, que registrou uma área basal de $50,43 \mathrm{~m}^{2} /$ ha ou $68,93 \%$ da DoR. O número de pinheiros foi estimado em 137 ind/ha. Os valores de VI e DoA dão suporte à grande importância dessa espécie e contribuíram para que, no passado, as FOM fossem denominadas Matas de Araucárias, pois eram consideradas formações vegetais homogêneas ocupadas apenas pela espécie caracterizadora (KLEIN, 1960). Contudo, os dados obtidos indicaram a existência de uma diversidade expressiva de espécies integrantes da composição florística e da estrutura da FOM (Quadro 1). A Araucaria angustifolia ocorreu como uma das seis espécies mais importantes 
na maioria dos estudos (Quadro 2), exceção em Barddal et al. (2004), que analisaram a estrutura de uma floresta em ambiente fluvial. Aárea basal foi o parâmetro decisivo para que o pinheiro-do-paraná obtivesse um VI elevado na amostra. Campomanesia xanthocarpa obteve o sexto lugar em VI (4,0\%) em Longhi e Faehser (1980) e Durigan (1999) com VI $=8,65 \%$, terceiro em Silva e Marconi (1990) com VI $=16,03 \%$. Capsicodendron dinisii foi a quarta espécie (VI $=5,04 \%)$ mais importante em Longhi e Faehser (1980) e Silva (2003) com VI =17,21\% e foi a quinta em Galvão et al. (1989), com VI=5,04\%. Casearia decandra foi a quarta espécie mais importante em Ziller (2002), com VI = 11,11\%; e a sexta em Silva (2003), com $\mathrm{VI}=12,11 \%$. Outras espécies do gênero Casearia se destacaram em Negrelle e Silva (1992), Rondon Neto et al. (2002a) e Silva e Marconi (1990). Allophylus edulis foi a segunda espécie em VI $=22,08 \%$, em Barddal et al. (2004), e Rondon Neto et al. (2002a), com VI=40,05\%.

Considerando o estudo de Galvão et al. (1989), que empregaram a fisionomia da vegetação ou a ocorrência de algumas espécies para nominar as associações com araucária, pode-se concluir que o remanescente do PMA se trata de uma associação de FOM com guabiroba (Campomanesia xanthocarpa). Por essa espécie ter sido a mais freqüente, apresentou a maior densidade de indivíduos e ficou em segundo lugar na estrutura da floresta pelo VI. Quanto ao Grupo 2, as espécies Zanthoxylum rhoifolium e Strychnos brasiliensis se destacaram pela DA $(46,88$ e 43,75 ind/ha, respectivamente), ficando em sétimo e oitavo lugares em número de indivíduos. Sebastiania commersoniana também mereceu atenção pela DA $(56,25 \mathrm{ind} / \mathrm{ha})$, porém essa espécie foi registrada em apenas sete parcelas $(F A=21,88 \%)$. A baixa freqüência demostra que essa espécie ocorre em agrupamentos, fato comprovado nas parcelas 26 e 27 , onde a espécie representou 25 e $31 \%$ da diversidade. Outro fator que se destacou em relação a Sebastiania commersoniana foi a instalação das parcelas em áreas de boa drenagem, sem sinais aparentes de hidromorfia, condição preferencial para o estabelecimento dessa espécie, conforme Barddal et al. (2004). Contudo, essa situação vem corroborar as observações de Curcio et al. (2004) de que os indivíduos dessa espécie ocorrem desde os solos hidromórficos até os não-hidromórficos. Vitex megapotamica, apesar de ser a $11^{a}$ espécie em VI\%, obteve a quinta colocação em DoA, com $1,15 \mathrm{~m}^{2} /$ ha resultante do maior diâmetro de seus poucos representantes amostrados. Das espécies do Grupo 3, nenhuma sobressaiu na análise dos parâmetros fitossociológicos. Esse grupo abrigou 8,5\% do número de indivíduos e $60 \%$ das espécies amostradas, com a ressalva de que 17 espécies (37,8\% do total) estavam representadas por apenas um indivíduo. A Figura 4 compara a distribuição dos valores de densidade, freqüência e dominância relativas na composição do valor de importância (VI\%), individualmente, das cinco espécies do Grupo 1 e no somatório das espécies dos Grupos 2, 3 e 4.

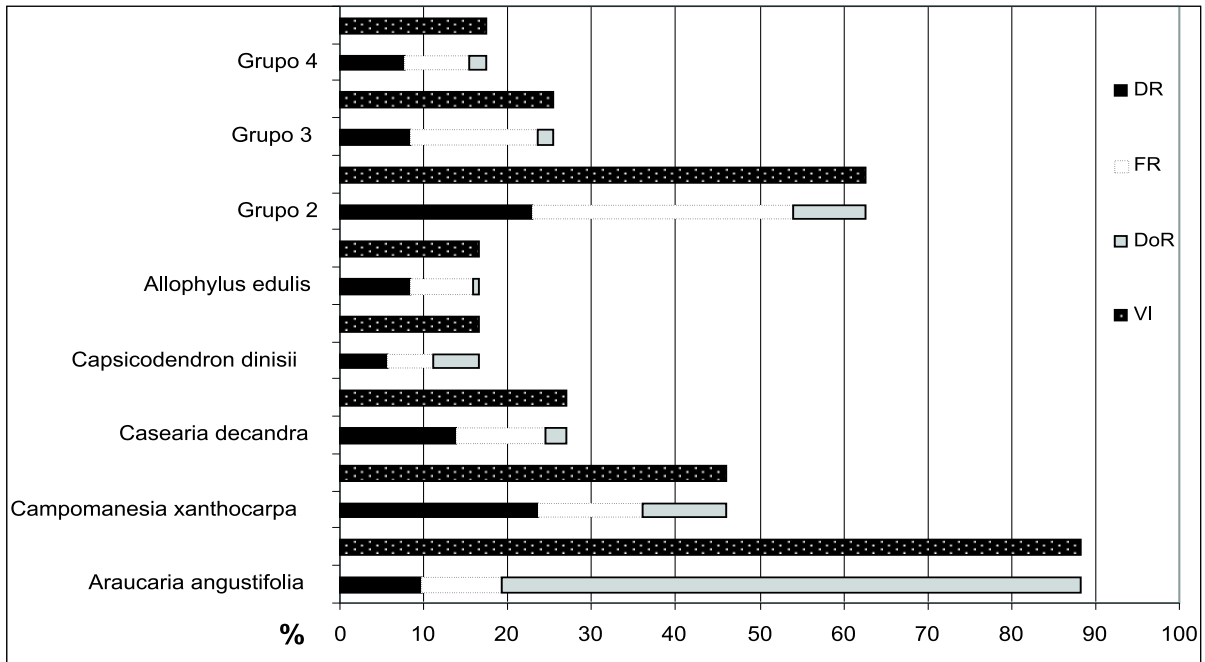

Figura 4 - Comparação da distribuição dos parâmetros fitossociológicos - densidade, frequiência e dominância relativas e valor de importância entre as cinco espécies do Grupo 1 com os Grupos 2, 3 e 4.

Figure 4-Comparison of the phytosociological parameter distribution-density, frequency and relative dominance and importance value among the 5 species of Group 1 with Groups 2, 3 and 4.

R. Árvore, Viçosa-MG, v.31, n.3, p.545-554, 2007 
A análise do histograma da Figura 4 permite considerar que, na Araucaria angustifólia, a DoR $(68,93 \%)$ é o principal parâmetro fitossociológico que influencia a composição de seu elevado VI\%. Para Campomanesia xanthocarpa $(\mathrm{DR}=23,49 \%)$ e Casearia decandra $(\mathrm{DR}=13,87 \%)$, a densidade relativa é o parâmetro preponderante na formação do VI\%, enquanto no Grupo 3 (FR $=15,1 \%)$ é a freqüência relativa. Notase nos Grupos $2(\mathrm{DR}=22,81, \mathrm{FR}=31,24 \%)$ e 4 (DR $=7,61, \mathrm{FR}=7,91 \%)$ e Allophylus edulis $(\mathrm{DR}=8,28$, $\mathrm{FR}=7,51 \%$ ) e a densidade e freqüência relativas são os parâmetros que mais influenciam o VI\%, e para Capsicodendron dinisii $(\mathrm{DR}=5,53 \%, \mathrm{FR}=5,59 \% \mathrm{e}$ $\operatorname{DoR}=5,53 \%)$ os valores dos três parâmetros são uniformes. Os valores dos parâmetros fitossociológicos calculados para os indivíduos mortos em pé influenciam a estrutura horizontal dos remanescentes de FOM, pois assumem posição considerável na classificação do VI\%. O valor calculado de 5,84\% para o VI\% faria com que a categoria "Mortas" obtivesse o quinto lugar geral neste estudo, sendo que em Nascimento et al. (2001), Barddal et al. (2004) e Silva (2003) ficaram em quarto lugar; em Durigan (1999) e Roderjan (2003), ficaram na terceira colocação.

Os DAPs dos indivíduos amostrados variaram de $4,8 \mathrm{~cm}$ a $114,7 \mathrm{~cm}$ e distribuídos em 22 classes. A distribuição mostrou que a quantidade de indivíduos nas classes de menor diâmetro foi decrescendo em direção às de maior diâmetro, com 89,9\% dos indivíduos concentrados nas cinco classes menores (4, 8 a 29,7 $\mathrm{cm})$, sendo que esse tipo de distribuição decrescente, segundo Machado et al. (1987), é característica de florestas naturais heterogêneas e multietâneas. Para Longhi e Faehser (1980), nas florestas tropicais multietâneas o maior número de indivíduos concentrase nas menores classes e vai decaindo nas classes de maior diâmetro, o que revela uma distribuição em "jota invertido", igualmente encontrado por Oliveira e Rotta (1982) e Silva (2003).

Das espécies que obtiveram os valores mais elevados de VI\% e se caracterizam como as espécies mais importantes na estrutura horizontal do remanescente estudado, Araucaria angustifolia está presente em $95,45 \%$ das classes diamétricas. Porém, sua maior ocorrência está concentrada nas classes de maior diâmetro. Campomanesia xanthocarpa está presente em oito classes, sendo que $96,2 \%$ de seus indivíduos estão nas cinco primeiras classes diamétricas. Dos indivíduos de Capsicodendron dinisii, $72 \%$ estão nas cinco primeiras classes diamétricas. E todos os indivíduos de Casearia decandra e Allophylus edulis estão concentrados nas classes até $29,7 \mathrm{~cm}$ de diâmetro.

Do total de 447 indivíduos amostrados, 151 indivíduos ou $33,78 \%$ pertencem ao estrato inferior. O estrato médio englobou 162 indivíduos, ou 36,24\%, e 134 indivíduos, ou $29,97 \%$, pertencem ao estrato superior. O estrato inferior é ocupado por 13 espécies; no estrato médio, aparecem 24 espécies, e no estrato superior encontram-se oito espécies. Verificou-se que Allophylus edulis, Araucaria angustifolia, Campomanesia xanthocarpa, Casearia decandra, Dalbergia frutescens, Eugenia pyriformis, Ilex brevicuspis, Ocotea pulchella e Sebastiania commersoniana são espécies que ocupam os três estratos. O menor indivíduo amostrado foi um exemplar de Dicksonia sellowiana com $1,3 \mathrm{~m}$, enquanto o maior foi um exemplar de Araucaria angustifólia, com $32 \mathrm{~m}$, a altura média entre todos os indivíduos ficou em 9,28 m. Semelhantemente como ocorreu com a distribuição diamétrica, a maior concentração de indivíduos ocorreu nas classes de menor altura, com 70,02\% dos indivíduos distribuídos em apenas $29,03 \%$ das classes de altura, ou seja, até os $11 \mathrm{~m}$. A Figura 5 ilustra a relação direta entre a altura e o diâmetro, com nítida concentração dos indivíduos arbóreos nas classes de altura até $11 \mathrm{~m}$ e até $24 \mathrm{~cm}$ de diâmetro.

O valor calculado do índice de diversidade de Shannon-Weaver foi de 2,79 nats/indivíduo. Esse valor ficou abaixo dos obtidos em outros estudos fitossociológicos em FOM (Quadro 2), demonstrando que o remanescente de FOM do PMA apresenta baixa diversidade de espécies. Para Roderjan et al. (2001), essa baixa diversidade florística é comum nos remanescentes de FOM localizadas em áreas de maior altitude, onde os rigores climáticos exercem pressão seletiva sobre a diversidade vegetal. Sobre o índice de uniformidade de Pielou $(\mathrm{J})$, pode-se considerar que a vegetação arbórea do remanescente estudado apresenta elevada uniformidade, uma vez que o valor calculado foi de 0,90.

Quanto à composição florística, o remanescente estudado apresentava a ocorrência de espécies companheiras típicas do pinheiro-do-paraná. Em relação à estrutura e dinâmica da floresta e levando em consideração o histórico da área, os valores dos parâmetros fitossociológicos, a área basal, o porte e os diâmetros dos indivíduos de Araucaria angustifolia, pode-se considerar que o remanescente de FOM do Parque Municipal das Araucárias se encontrava num estágio médio a avançado de sucessão natural.

R. Árvore, Viçosa-MG, v.31, n.3, p.545-554, 2007 


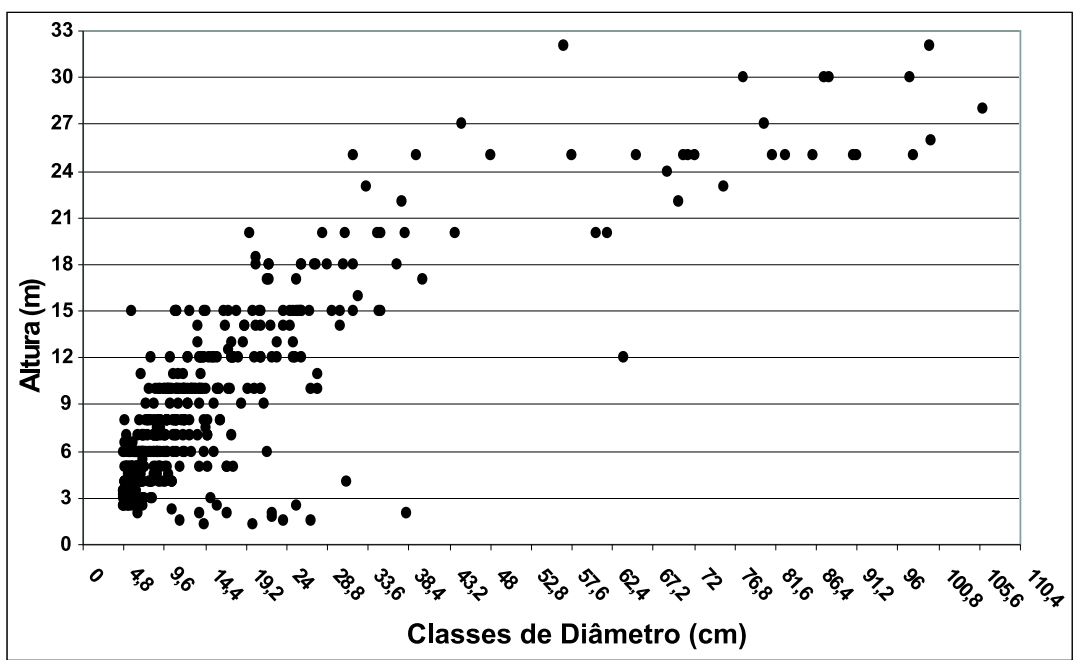

Figura 5 - Distribuição direta do número de indivíduos por altura e diâmetro das espécies encontradas no remanescente de FOM do Parque Municipal das Araucárias, em Guarapuava, PR.

Figure 5 -Direct distribution of the number of individuals per height and diameter of the species found within the MOF remnant in the Araucaria Municipal Park, Guarapuava, PR.

Quadro 2 - Indices de Diversidade de Shannon-Weaver (H') calculados em remanescentes do FOM

Table 2 - Shannon-Weaver diversity indexes ( $\left.H^{\prime}\right)$ for MOF remnants

\begin{tabular}{lc}
\hline \multicolumn{1}{c}{ Estudo } & $\begin{array}{c}\text { Índice de } \\
\text { Shannon-Weaver (H') }\end{array}$ \\
\hline Negrelle e Silva (1992) & 8,11 \\
Negrelle e Leuchtenberger (2001) & 3,538 \\
Durigan (1999) & 3,516 \\
Rondon Neto et al. (2002a) & 3,437 \\
Silva (2003) & 3,36 \\
Nascimento et al. (2001) & 3,0 \\
Roderjan (2003) & 2,801 \\
Rondon Neto et al. (2002b) & 2,768 \\
Este Estudo & 2,79 \\
\hline
\end{tabular}

\section{REFERÊNCIAS}

\section{APG II - ANGIOSPERM PHYLOGENY GROUP.}

An update of the Angiosperm Phylogeny Group classification for the orders and families of flowering plants: APG II. Botanical

Journal of the Linnean Society, n.141, p.399-436, 2003.

BARDDAL, M. L. et al. Fitossociologia do sub-bosque de uma floresta ombrófila mista aluvial, no município de Araucária, PR.

Revista de Ciência Florestal, v.14, n.1, p.35-45, 2004.

R. Árvore, Viçosa-MG, v.31, n.3, p.545-554, 2007
BRAUN-BLANQUET, J. Sociología vegetal estudio de las comunidades vegetales. Buenos Aires : ACME AGENCY, 1950. p.26-79.

CIATEC S.A. Mata nativa - Sistema para análise fitossociológica e elaboração de planos de manejo de florestas nativas. Viçosa, MG: 2001. CD-ROM.

CURCIO, G. R.; BONNET A.; BARDDAL, M. L. A floresta em ambientes fluviais. - Guia dirigido. Colombo: 2004.

DURIGAN, M. E. Florística, dinâmica e análise protéica de uma Floresta Ombrófila Mista em São João do Triunfo - Pr. 1999. 83f. Dissertação (Mestrado em Engenharia Florestal) - Universidade Federal do Paraná, Curitiba, 1999.

FARIAS, C. A. et al. Comparação de métodos de amostragem para análise estrutural de florestas ineqüiâneas. Revista Árvore, v.26, n.5, p.541-548, 2002.

FONSECA, R. C. B.; FONSECA, I. C. B. Utilização de métodos estatísticos multivariados na caracterização do mosaico sucessional em floresta semidecídual. Revista Árvore, v.28, n.3, p.351-359, 2004. 
FUNDAÇÃO DE PESQUISAS FLORESTAIS DO PARANÁ - FUPEF. Conservação do bioma floresta com araucária: relatório final Diagnóstico dos remanescentes florestais. Curitiba: FUPEF, 2001.2v.

GALVÃO, F.; KUNIYOSHI, Y. S.; RODERJAN, C. V. Levantamento fitossociológico das principais associações arbóreas da Floresta Nacional de Irati Pr. Revista Floresta, v.19, n.1/2, p.30-49, 1989.

INSTITUTO AGRONÔMICO DO PARANÁ IAPAR. Guia de campo para identificação de solos no Estado do Paraná - solos da região do $3^{\circ}$ Planalto. Londrina: Fundação do Instituto Agronômico do Paraná, 1986.

INSTITUTO AGRONÔMICO DO PARANÁ. IAPAR Cartas climáticas - médias históricas. Disponível em Disponível em: <http://www.iapar.pr.gov.br. Acesso em 15 de jan. 2006.

\section{INSTITUTO BRASILEIRO DE GEOGRAFIA E} ESTATÍSTICA - IBGE. Manual técnico da vegetação brasileira.. Rio de Janeiro: IBGE, 1992 (Série - Manuais Técnicos em Geociências, n.1).

ISERNHAGEN, I. A fitossociologia florestal no Paraná e os programas de recuperação de áreas degradadas: uma avaliação. 2001. 134f. Dissertação (Mestrado em Botânica) - Universidade Federal do Paraná, Curitiba, 2001.

KLEIN, R. M. O aspecto dinâmico do pinheiro brasileiro. Selowia, n.12, p.17-44, 1960.

KLEIN, R. M. Aspectos dinâmicos da vegetação do sul do Brasil. Selowia, n.36, p.5-54, 1984.

LONGHI, S. J.; FAEHSER, L. E. H. A estrutura de uma floresta natural de Araucaria angustifolia (Bertol.) O. Kuntze. no sul do Brasil. In: IUFRO MEETING ON FORESTRY PROBLEMS OF THE GENUS ARAUCARIA. 1979, Curitiba. Anais... Curitiba: FUPEF, 1980. p.167-172.

MAACK, R. Geografia física do Estado do Paraná. 2.ed. Rio de Janeiro: José Olympio, 1981.450p.
MACHADO, S. A.; BARTOSZEK, A. C. P. S.; OLIVEIRA, E. B. Estudo da estrutura diamétrica para Araucaria angustifolia em florestas naturais nos estados da região sul do Brasil. Revista Floresta, v.1/2, n.26, p.59-70, 1997.

MAGURRAN, A. E. Ecological diversity and its measurement. Princeton: Princeton University Press, 1988. 179p.

MATTEUCCI, S. D.; COLMA, A. Metodologia para el estudo de la vegetacion. Washington: OEA/PRDECT, 1982. 168p.

MISSOURI BOTANICAL GARDEN. w3 tropics. Disponível em: <http://mobot.mobot.org/W3T/ Search/vast.html> Acesso em: 10 jan. 2006.

MUELLER-DUMBOIS, D.; ELLENBERG, H. Aims and methods vegetation ecology. New York: John Wiley \& Sons, 1974. 547p.

NASCIMENTO, A. R. T.; LONGHI, S. J.; BRENA, D. A. Estrutura e padrões de distribuição espacial de espécies arbóreas em uma amostra de floresta ombrófila mista em Nova Prata, RS. Revista de Ciência Florestal, v.11, n.1, p.105-119, 2001.

NEGRELLE, R. A. B.; SILVA, F. C. Fitossociologia de um trecho de floresta com Araucaria angustifolia (Bert.) O. Ktze. No município de Caçador-Sc. Boletim de Pesquisa Florestal, n.24/25, p.37-54, 1992.

NEGRELLE, R. A. B.; LEUCHTENBERGER, R. Composição e estrutura do componente arbóreo de um remanescente de floresta ombrófila mista. Revista Floresta, v.1/2, n.31, p.42-51, 2001.

OLIVEIRA, Y. M. M.; ROTTA, E. Levantamento da estrutura horizontal de uma mata de Araucária do primeiro planalto paranaense. Boletim de Pesquisa Florestal, n.4, p.1-45, 1982.

RICE, E. L.; KELTING, R. W. The species-area curve. Ecology, v.36, n.1, p.7-12, 1955.

RODERJAN, C. V. Diagnóstico da cobertura vegetal da área proposta para a construção da PCH São Jerônimo e do contexto vegetacional do seu entorno. Curitiba: FUPEF, 2003. 90p.

R. Árvore, Viçosa-MG, v.31, n.3, p.545-554, 2007 
RODERJAN. C. V.; MILANO, M. S.; FIRKOWSKI, C. Plano de manejo do Parque Municipal das Araucárias. Guarapuava: SEMAFLOR, 1991. 70p.

RODERJAN, C. V.et al. Caracterisation des unites phytogeographiques dans l'etat du Paraná, Brasil, et leur etat de conservation. Biogeographica, n.77, v.4, p.129-140, 2001.

ROMARIZ, D. A. A vegetação. In: AZEVEDO, A. Brasil - A terra e o homem - As bases físicas. 2.ed. São Paulo: Companhia Editora Nacional, 1972. v.1. p.521-548.

RONDON NETO, R. M. et al. Caracterização florística e estrutural de um fragmento de floresta ombrófila mista, em Curitiba, Pr - Brasil. Revista Floresta, v.1, n.32, p.3-16, 2002a.

RONDON NETO, R. M. et al. Análise florística e estrutural de um fragmento de floresta ombrófila mista montana, situado em Criúva, RS - Brasil.

Revista de Ciência Florestal, v.12, n.1, p. 29-37, 2002b.

GUARAPUAVA - Prefeitura Municipal Secretaria Municipal do Meio Ambiente. SEMAFLOR. Disponível em:

Www.prefeituramunicipaldeguarapuava/. Acesso em 5 jan. 2006.

GUARAPUAVA - SECRETARIADE PLANEJAMENTO URBANO - SEPLUG. Mapa de localização do Município de Guarapuava. Guarapuava: 2005.
SILVA, C. S.; MARCONI, L. P.Fitossociologia em uma floresta com araucária em Colombo - Pr. Boletim de Pesquisa Florestal, n.20, p.23-38, 1990.

SILVA, A. S.; SALOMÃO, A. N.; NETTO, D. A. M. Natural regeneration under Araucaria angustifolia (Bert.) O. Kuntze forest in the Genetic Reserve of Caçador-SC. Revista Árvore, v.22, n.2, p.143-153, 1998.

SILVA, D. W. Florística e fitossociologia de dois remanescentes de floresta ombrófila mista (Floresta com Araucária) e análise de duas populações de araucaria angustifolia (Bertol.) O. Kuntze na região de Guarapuava, Pr. 2003. 160f. Tese (Doutorado em Ecologia) - Universidade Federal de São Carlos, São Carlos, 2003.

SOCIEDADE DE PROTEÇÃODA VIDASELVAGEM - SPVS. Nossas árvores - manual para a recuperação da reserva florestal legal. Curitiba: FNMA, 1996.

SOUZA, D. R. et al. Emprego de análise multivariada para estratificação vertical de florestas inequiâneas. Revista Árvore, v.27, n.1, p.59-63, 2003.

ZILLER, S. R. A estepe gramíneo-lenhosa no segundo planalto do Paraná: diagnóstico ambiental com enfoque à contaminação biológica. 2000. 242f. Tese (Doutorado em Ciências Florestais) Universidade Federal do Paraná, Curitiba, 2000. 